\title{
Electrochemical comparison of $\mathrm{IrO}_{2}$ prepared by anodic oxidation of pure iridium and $\mathrm{IrO}_{2}$ prepared by thermal decomposition of $\mathrm{H}_{2} \mathrm{IrCl}_{6}$ precursor solution
}

\author{
Lassiné Ouattara $\cdot$ Stéphane Fierro $\cdot$ \\ Olivier Frey · Milena Koudelka · Christos Comninellis
}

Received: 10 October 2008/ Accepted: 26 January 2009/Published online: 18 February 2009

(C) Springer Science+Business Media B.V. 2009

\begin{abstract}
Surface redox activities, oxygen evolution reaction (OER), oxidation of formic acid (FA), and anodic stability were investigated and compared for $\mathrm{IrO}_{2}$ electrodes prepared by two techniques: the thermal decomposition of $\mathrm{H}_{2} \mathrm{IrCl}_{6}$ precursor (TDIROF) and the anodic oxidation of metallic iridium (AIROF). Surface redox activities involved on the AIROF were found to be much faster than those involved on the TDIROF. Concerning the oxygen evolution reaction, both films show a similar mechanism and specific electrocatalytic activities. The situation seems to be different for FA oxidation. In fact, on TDIROF, the oxidation of FA and the OER compete involving the same surface redox couple $\operatorname{Ir}(\mathrm{VI}) / \mathrm{Ir}(\mathrm{IV})$ contrary to FA oxidation on AIROF, where the $\operatorname{Ir}(\mathrm{V}) / \mathrm{Ir}(\mathrm{IV})$ surface redox couple is involved. Finally, electrode stability measurements have shown that contrary to TDIROF, which are very stable under anodic polarization, the AIROF are rapidly corroded under anodic treatment. This corrosion is enhanced even further in the presence of formic acid.
\end{abstract}

\section{Ouattara}

Laboratoire de Chimie Physique, UFR SSMT, Université

de Cocody, 22 BP 582, Abidjan 22, Ivory Coast

\section{S. Fierro $(\bowtie) \cdot$ C. Comninellis $(\bowtie)$}

Institute of Chemical Sciences and Engineering,

Swiss Federal Institute of Technology, ISIC-EPFL,

CH-1015 Lausanne, Switzerland

e-mail: stephane.fierro@epfl.ch

C. Comninellis

e-mail: christos.comninellis@epfl.ch

O. Frey · M. Koudelka

The Sensors, Actuators and Microsystems Laboratory, Institute of Microtechnology, University of Neuchâtel, SAMLABUNINE, Jaquet-Droz 1, 2007 Neuchâtel, Switzerland
Keywords TDIROF - AIROF - Surface redox activity · Oxygen evolution · Formic acid oxidation .

Anodic stability

\section{Introduction}

Iridium dioxide electrodes form part of the dimensionally stable anodes $\left(\mathrm{DSA}^{\circledR}\right)$, which are widely used in industry for metal electro-winning, cathodic protection, and electroorganic synthesis [1-4].

The first iridium dioxide electrodes, as described in the corresponding patents $[5,6]$, were thermally decomposed iridium oxide films (TDIROF) produced by thermal decomposition of the appropriate precursor solution on an inert substrate such as titanium or tantalum.

Later, other techniques of conductive $\mathrm{IrO}_{2}$ film formation such as the anodic oxidation of metallic iridium were considered. In fact, it has been shown that pure iridium and mostly the corresponding anodic iridium oxide film (AIROF) formed through potential cycling exhibit some interesting electrochemical properties and especially toward the oxygen evolution reaction (OER) [7-9].

Although the activity and stability of AIROF and TDIROF toward OER have been widely studied [1-4, 10-12], the mechanisms involved in the process are still a matter of discussion.

More recently, the electro-catalytic activity of TDIROF toward the oxidation of organics has been described. However, little is known about the surface redox activity and stability during the oxidation of organics on AIROF.

However, as the participation of the TDIROF coating via the $\mathrm{IrO}_{3} / \mathrm{IrO}_{2}$ redox couple during OER and the oxidation of formic acid in acidic media has been proved 
recently using DEMS $[13,14]$, the aim of the present study is to compare an $\mathrm{IrO}_{2}$ electrode prepared by anodic oxidation of pure $\mathrm{Ir}$ (AIROF) with an $\mathrm{IrO}_{2}$ electrode prepared by thermal decomposition of a precursor solution (TDIROF) by investigating the surface redox activities in the water stability potential region as well as during the OER and the oxidation of formic acid as model organic compound.

\section{Experimental}

All electrochemical experiments were performed in a classical three-electrode cell $(70 \mathrm{~mL})$ using an Autolab PGSTAT 30. The counter electrode was a Pt wire; the reference electrode was $\mathrm{Hg} / \mathrm{Hg}_{2} \mathrm{SO}_{4} / \mathrm{K}_{2} \mathrm{SO}_{4}$ (sat.) (MSE; $0.65 \mathrm{~V}$ vs. SHE) and two different working electrodes were used:

(a) Anodic iridium oxide film electrode (AIROF): An iridium film $(0.1 \mu \mathrm{m})$ was deposited by sputtering on $\mathrm{p}$-Si $\left(0.0054 \mathrm{~mm}^{2}\right)$ using a thin $(0.02 \mu \mathrm{m})$ tantalum interlayer (p-Si/Ir). The anodic iridium oxide film (AIROF) was formed through potential cycling of this electrode between -0.05 and $1.45 \mathrm{~V}$.

(b) $\mathrm{An} \mathrm{IrO}_{2}$ electrode prepared by thermal decomposition of a precursor (TDIROF): the $\mathrm{IrO}_{2}$ film $(0.35 \mathrm{mg}$ $\mathrm{cm}^{-2}$ ) was deposited on disc-shaped sandblasted $\mathrm{p}-\mathrm{Si}$ $\left(182.25 \mathrm{~mm}^{2}\right)$ by the thermal decomposition of a $\mathrm{H}_{2} \mathrm{IrCl}_{6}(99.9 \%$, ABCR) precursor solution in air at $500^{\circ}$ (TDIROF). The presence of iridium dioxide on the substrate was verified using XPS measurements (not presented).

All potentials in this work are with respect to the standard hydrogen electrode (SHE).

\section{Results and discussion}

\subsection{Surface redox activities}

The cyclic voltammetry measurements of $\mathrm{IrO}_{2}$ films prepared by the thermal decomposition technique (TDIROF), recorded for three potential windows in the potential range between 0.0 and $1.4 \mathrm{~V}$ and presented in Fig. 1, show two main features:

- The charge involved in the anodic scan is completely recovered during the cathodic scan $\left(q_{+}=q_{-}\right)$for all the scan rates investigated $\left(10-500 \mathrm{mV} \mathrm{s}^{-1}\right)$. However, the $\mathrm{CV}$ shows an axial symmetry (around the potential axis) only if the lower potential limit is higher than $0.4 \mathrm{~V}$. In fact, at lower potential limits, a strong distortion of the $\mathrm{CV}$ around the potential axis is observed. This is an indication that the surface processes involved at low potentials $(<0.4 \mathrm{~V})$ are slow.

- The TDIROF are completely inactive toward the electrochemical reduction of dissolved oxygen (aerated and de-aerated solutions give the same $\mathrm{CV}$ ).

- Furthermore, from measurements of the apparent activation energy $\left(E_{\mathrm{a}}\right)$ for the charging/discharging process using TDIROF reported in a previous paper [15], we have to consider two contributions. The first contribution is due to a fast (instantaneous) process with zero activation energy related to the charging of the electrical doublelayer at the electrode-electrolyte interface and the second is related with the slow diffusion of protons within the $\mathrm{IrO}_{2}$ coating inducing surface redox activities (Eq. 1) with an activation energy around $2.4 \mathrm{~kJ} \mathrm{~mol}^{-1}$ [15].

$\mathrm{IrO}_{x}(\mathrm{OH})_{y}+\delta \mathrm{H}^{+}+\delta \mathrm{e}^{-} \underset{\text { anodic }}{\stackrel{\text { cathodic }}{\rightleftarrows}} \operatorname{IrO}_{x-\delta}(\mathrm{OH})_{y+\delta}$

The cyclic voltammetry measurements of $\mathrm{IrO}_{2}$ films prepared by the anodic oxidation of metallic iridium
Fig. 1 Cyclic voltammograms using TDIROF $\left(\mathrm{IrO}_{2}\right.$ loading: $0.273 \mathrm{mg} \mathrm{cm}^{-2}$ ) at $100 \mathrm{mV} \mathrm{s}^{-1}$ for different potential windows $a$ between 0.3 and $1.1 \mathrm{~V}$, $b$ between 0.3 and $1.4 \mathrm{~V}$, $c$ between 0 and $1.4 \mathrm{~V}$. Supporting electrolyte: $1 \mathrm{M}$ $\mathrm{HClO}_{4} \cdot T=25{ }^{\circ} \mathrm{C}$

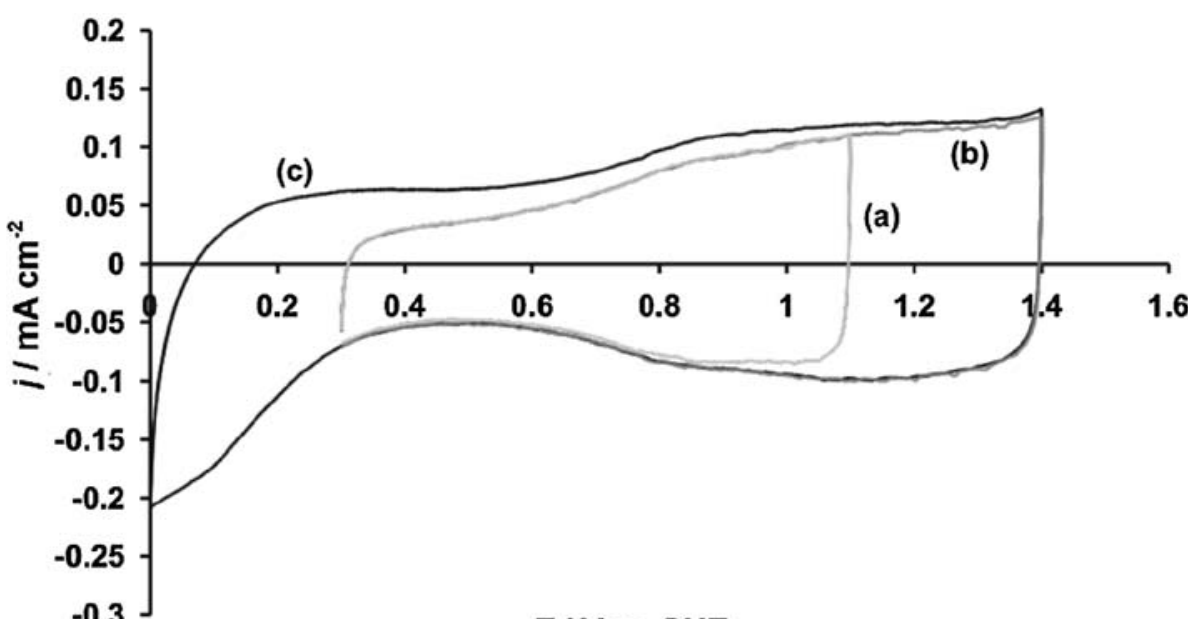

EIV vs SHE 
Fig. 2 Successive cyclic voltammograms (three scan number intervals: from scan 1 to scan 40; from scan 90 to scan 130 and from scan 150 to scan 350) using a $\mathrm{p}-\mathrm{Si} / \mathrm{Ir}$ electrode at $50 \mathrm{mV} \mathrm{s}^{-1}$ between -0.05 and $1.45 \mathrm{~V}$. Supporting electrolyte: $1 \mathrm{M} \mathrm{H}_{2} \mathrm{SO}_{4} . T=25{ }^{\circ} \mathrm{C}$. $a$ hydrogen evolution domain, $b$ reduction of dissolved $\mathrm{O}_{2}$ domain, $c$ pre-peak, $d$ redox couple $\operatorname{Ir}(\mathrm{IV}) / \mathrm{Ir}(\mathrm{III}), e$ redox couple $\operatorname{Ir}(\mathrm{V}) / \mathrm{Ir}(\mathrm{IV})$ and $f$ oxygen evolution reaction domain

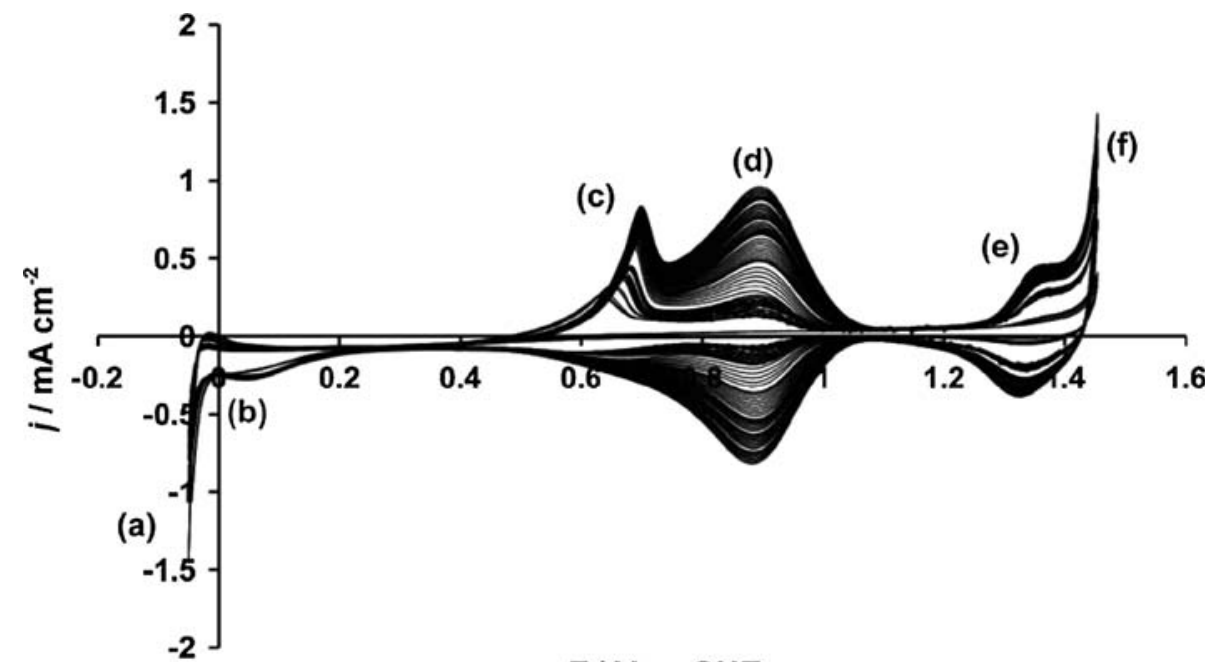

E / V vS SHE
(AIROF) are very different form those obtained using TDIROF. These anodic films are obtained by cycling the potential in the range between -0.05 and $1.45 \mathrm{~V}$. Figure 2 shows three series of consecutive CV scans (from scan 1 to scan 40, from scan 90 to scan 130 and from scan 150 to scan 350 ) recorded at $50 \mathrm{mV} \mathrm{s}^{-1}$ in $1 \mathrm{M} \mathrm{H}_{2} \mathrm{SO}_{4}$ using a metallic iridium electrode. The results are in very good accordance with similar CV curves found in literature $[11,12]$. The first voltammograms show almost no surface activity between hydrogen evolution at $-0.05 \mathrm{~V}$ (Region (a) in Fig. 2) and oxygen evolution at $1.45 \mathrm{~V}$ (Region (f) in Fig. 2), which are the first signals to appear together with dissolved $\mathrm{O}_{2}$ reduction at $0.2 \mathrm{~V}$ (Region (b) in Fig. 2) in aerated solution. This last reaction has been clearly identified as no activity was observed in that potential region when using de-aerated solutions.

After approximately 50 scans, three anodic peaks appear at $0.65 \mathrm{~V}$ (peak (c) in Fig. 2), $0.9 \mathrm{~V}$ (peak (d) in Fig. 2) and $1.2 \mathrm{~V}$ (peak (e) in Fig. 2). The irreversible peak (c) (reported as pre-peak) is the first to appear followed by the reversible peaks (d) and (e) before oxygen evolution.

The pre-peak is progressively shifted toward more positive potentials with increasing scan number (from $0.65 \mathrm{~V}$ for scan number 50 to $0.7 \mathrm{~V}$ for scan number 350 ); however, the position of peaks (d) and (e) are only slightly shifted with increasing scan number. These shifts are certainly related to the reversibility of the surface processes involved.

Figure 3 shows CV measurements of AIROF obtained in the potential range between -0.05 and $1.25 \mathrm{~V}$ then moving toward the upper potential limit with increments of $20 \mathrm{mV}$ up to $1.49 \mathrm{~V}$. This figure shows clearly that the reduction of dissolved oxygen at $0.2 \mathrm{~V}$ is strongly related with the oxygen evolution reaction, which has an onset potential of about $1.36 \mathrm{~V}$.
The surface reactions related to redox couples (d) and (e) have been discussed in literature $[11,12]$ and are believed to be the following: At $0.9 \mathrm{~V}$, peak (d) on fig. 2:

$$
\mathrm{Ir}(\mathrm{OH})_{3} \rightleftarrows \mathrm{IrO}(\mathrm{OH})_{2}+\mathrm{H}^{+}+\mathrm{e}^{-}
$$

At $1.35 \mathrm{~V}$, peak (e) on fig. 2:

$$
\mathrm{IrO}(\mathrm{OH})_{2} \rightleftarrows \mathrm{IrO}_{2}(\mathrm{OH})+\mathrm{H}^{+}+\mathrm{e}^{-}
$$

These cyclic voltammetry measurements show that TDIROF and AIROF have different kinetics for the involved surface redox activity. In fact, on iridium dioxide prepared through thermal decomposition (TDIROF), the surface process is slow while on the oxide film prepared anodically (AIROF), numerous fast surface redox reactions are involved. Furthermore, AIROF are active toward the reduction of dissolved oxygen contrary to TDIROF, which is inactive toward the same process.

These differences are mainly due do the preparation technique of the electrode. In fact, AIROF are produced under mild conditions involving the anodic oxidation at room temperature through potential cycling of pure iridium metal. It has been shown that this method yields much more hydrated $\mathrm{IrO}_{2}$ with higher bulk defect densities compared to TDIROF [16]. Furthermore, it has been shown that treating the AIROF at high temperature, which implies the loss of water molecules, yields to an electrode whose behavior tend to approach the one of TDIROF [8]. It is therefore clear that the observed differences in the surface processes between TDIROF and AIROF are related to the hydratation of the obtained oxide.

\subsection{The oxygen evolution reaction}

Figure 4 shows a typical steady polarization curve for the OER on TDIROF electrodes in $1 \mathrm{M} \mathrm{HClO}_{4}$. In the same 
Fig. 3 Cyclic voltammograms recorded at $50 \mathrm{mV} \mathrm{s}^{-1}$ using AIROF for different potential windows: the lower cut-off was fixed at $-0.05 \mathrm{~V}$ while the higher cut-off varies from 1.25 to $1.49 \mathrm{~V}$ with increments of $20 \mathrm{mV}$. Supporting electrolyte: $1 \mathrm{M} \mathrm{H}_{2} \mathrm{SO}_{4} . T=25{ }^{\circ} \mathrm{C}$

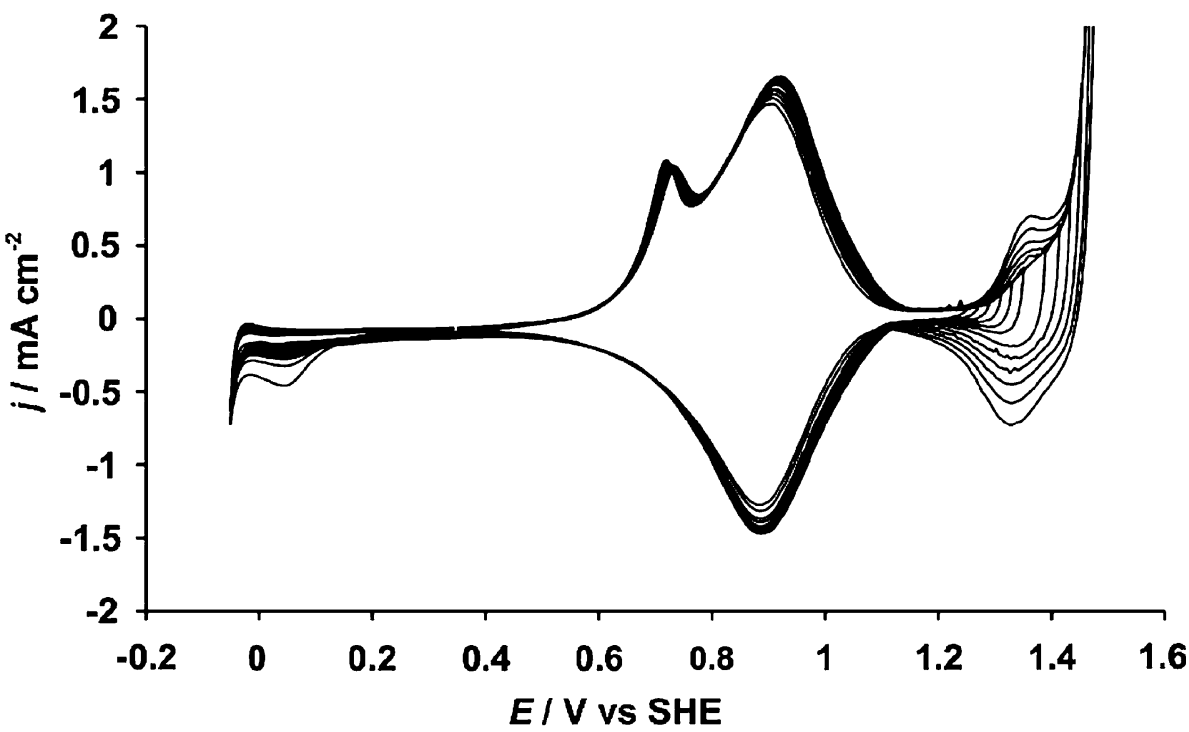

Fig. 4 Steady-state polarization curves recorded between 1.4 and $1.52 \mathrm{~V}$ using TDIROF $\left(\mathrm{IrO}_{2}\right.$ loading: $0.35 \mathrm{mg} \mathrm{cm}^{-2}$ ). Inset Corresponding IR dropcorrected Tafel plot. Supporting electrolyte: $1 \mathrm{M} \mathrm{HClO}_{4}$. $T=25{ }^{\circ} \mathrm{C}$

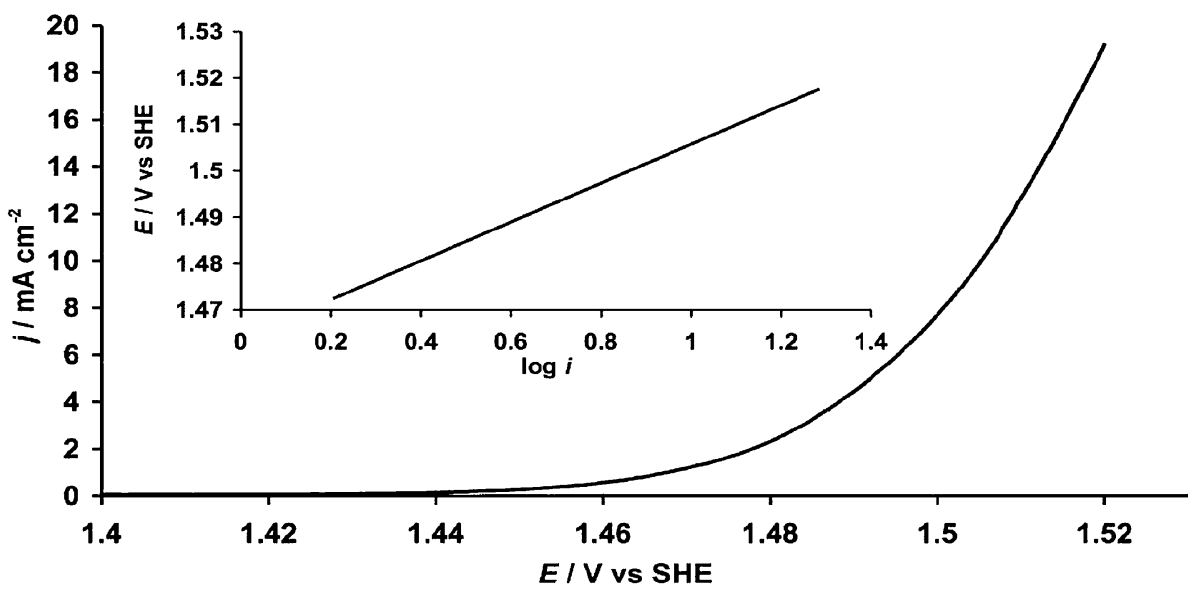

figure, the corresponding Tafel plot obtained after IR drop correction (inset of Fig. 4) is also given. It can be seen that even at high overpotentials, the IR drop-corrected Tafel plot gives a linear relation with a slope of about $40 \mathrm{mV} /$ decade.

It is worthwhile to notice that these polarization measurements are reproducible even after treatment of the electrode for a long period of time (several hours) at high anodic potentials $(>1.5 \mathrm{~V})$. This is an indication of the high anodic stability of the TDIROF.

Figure 5 shows IR drop corrected Tafel plots obtained for a fresh iridium electrode (p-Si/Ir) ((a) on Fig. 5) and for AIROF ((b) on Fig. 5) formed by potential cycling (50 cycles at $50 \mathrm{mV} \mathrm{s}^{-1}$ between -0.05 and $1.45 \mathrm{~V}$ ).

This figure shows clearly that the Tafel slope for the OER changes from $120 \mathrm{mV} /$ decade for the Ir metal to $40 \mathrm{mV} /$ decade for the AIROF indicating that the rate determining step of the OER on pure iridium differs from the one occurring on AIROF.
In acid medium, the following reaction path (Eqs. 4, 5 and 6) was proposed for the oxygen evolution reaction (OER) on active oxide electrodes [17].

$\mathrm{S}+\mathrm{H}_{2} \mathrm{O} \rightarrow \mathrm{S}-\mathrm{OH}_{\mathrm{ads}}+\mathrm{H}^{+}+\mathrm{e}^{-}$

$\mathrm{S}-\mathrm{OH} \rightarrow \mathrm{S}-\mathrm{O}_{\mathrm{ads}}+\mathrm{H}^{+}+\mathrm{e}^{-}$

$\mathrm{S}-\mathrm{O} \rightarrow \mathrm{S}+\frac{1}{2} \mathrm{O}_{2}$

where $\mathrm{S}$ stands for active sites and $\mathrm{OH}_{\mathrm{ads}}, \mathrm{O}_{\mathrm{ads}}$ are adsorption intermediates.

This mechanism predicts the following Tafel slopes: $120 \mathrm{mV} /$ decade if step 4 is the rate-determining step (rds), $40 \mathrm{mV} /$ decade for step 5 and $30 \mathrm{mV} /$ decade for step 6 .

The measured Tafel slopes indicate that water discharge (step 4) is the rds for the OER on metallic iridium (Tafel slope $120 \mathrm{mV} /$ decade) and formation of a higher oxide (step 5) is the rds in case of $\mathrm{IrO}_{2}$ formed either by the anodic oxidation of metallic Ir (AIROF) or by the thermal 

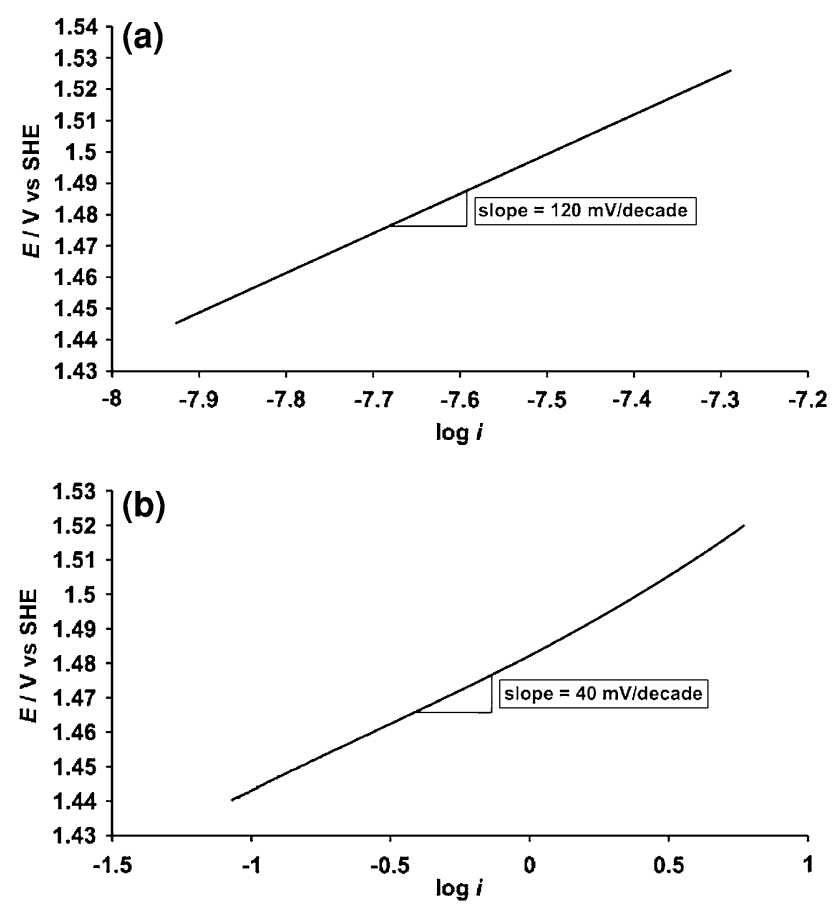

Fig. 5 IR drop-corrected Tafel slopes recorded between 1.44 and $1.52 \mathrm{~V}$ corresponding to: a fresh $\mathrm{p}-\mathrm{Si} / \mathrm{Ir}$ electrode, b AIROF. Supporting electrolyte: $1 \mathrm{M} \mathrm{H}_{2} \mathrm{SO}_{4} . T=25{ }^{\circ} \mathrm{C}$

decomposition of a precursor solution (TDIROF). This is an indication that the same mechanism of OER is involved on both AIROF and TDIROF. The participation of the higher oxide in the OER on TDIROF via the $\mathrm{IrO}_{3} / \mathrm{IrO}_{2}$ redox couple has been recently demonstrated using ${ }^{18} \mathrm{O}$ labelling together with differential electrochemical mass spectrometry (DEMS) measurements [13].

It is worthwhile to notice that the treatment of the AIROF at high potentials $(>1.6 \mathrm{~V})$ for a few minutes results in an increase of Tafel slope from 40 to $120 \mathrm{mV} /$ decade. This is an indication that at these potentials, the anodically formed film is corroded as already reported by others $[10,18]$.

Figure 6 shows that the normalized polarization curves (the current is reported relative to the voltammetric charge measured from the CV curves between -0.05 and $1.45 \mathrm{~V}$ at $50 \mathrm{mV} \mathrm{s}^{-1}$ ) for the OER are almost the same for both TDIROF and AIROF electrodes. This is an indication that both electrodes have almost the same specific electrocatalytic activity.

However, it is worthwhile to mention that the obtained Tafel plots for the OER using TDIROF in this work (40 mV/decade) are different from those reported by others. In fact, a Tafel slope of $60 \mathrm{mV} / \mathrm{dec}$ ade for the OER in acidic media has been usually reported [17, 19]. A very intriguing reaction path involving $\mathrm{S}-\mathrm{OH}_{\mathrm{ads}}$ intermediates with different energy states has been proposed by these authors in order to explain this abnormal Tafel slope

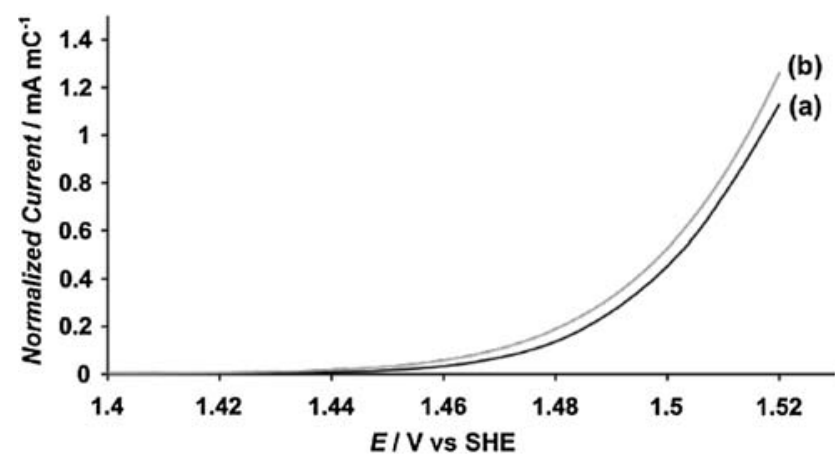

Fig. 6 Normalized steady-state polarization curves using: $a$ the AIROF, $b$ the TDIROF ( $\operatorname{IrO}_{2}$ loading: $0.35 \mathrm{mg} \mathrm{cm}^{-2}$ ). The current has been normalized relative to the voltammetric charge measured between -0.05 and $1.45 \mathrm{~V}$ at $50 \mathrm{mV} \mathrm{s}^{-1} . T=25^{\circ} \mathrm{C}$

[17, 19]. Problems related with uncompensated IR drop correction and partial blockage of the electrode surface by the evolved oxygen are certainly related with the reported abnormal Tafel slopes. In the present study, the experiments have been carefully conducted in order to avoid these problems.

\subsection{Oxidation of organics using formic acid as a model compound}

Figure 7 shows steady-state polarization curves obtained on TDIROF in $1 \mathrm{M} \mathrm{HClO}_{4}$ containing different concentration of Formic Acid (FA). The shift of these I-V curves toward less positive potentials in presence of FA is related with the involvement of the same redox couple $\mathrm{IrO}_{3} / \mathrm{IrO}_{2}$ in both the oxygen evolution reaction (Eq. 9) and FA oxidation (Eq. 10) competing during the process according to the reaction path given in Eq. 7-10.

$\mathrm{IrO}_{2}+\mathrm{H}_{2} \mathrm{O} \rightarrow \mathrm{IrO}_{2}(\mathrm{OH})_{\text {ads }}+\mathrm{H}^{+}+\mathrm{e}^{-}$

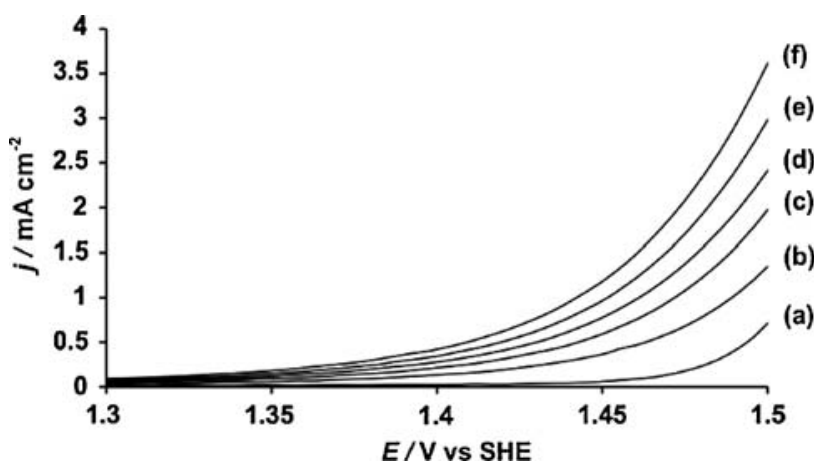

Fig. 7 Steady-state polarization curves between 1.3 and $1.5 \mathrm{~V}$ using TDIROF ( $\mathrm{IrO}_{2}$ loading: $0.35 \mathrm{mg} \mathrm{cm}{ }^{-2}$ ) for different concentration of formic acid: $a 0 \mathrm{mM}, b 195.33 \mathrm{mM}, c 387.78 \mathrm{mM}, d 577.4 \mathrm{mM}, e$ $764.25 \mathrm{mM}$ and $f 948.41 \mathrm{mM}$. Supporting electrolyte: $1 \mathrm{M} \mathrm{HClO}_{4}$. $T=25^{\circ} \mathrm{C}$ 
Fig. 8 Cyclic voltammograms recorded at $100 \mathrm{mV} \mathrm{s}^{-1}$ between 1.055 and $1.425 \mathrm{~V}$ using AIROF for different concentration of formic acid: $a 0 \mathrm{mM}, b 100 \mathrm{mM}, c 250 \mathrm{mM}$, $d 500 \mathrm{mM}$ and $e 750 \mathrm{mM}$. Supporting electrolyte: $1 \mathrm{M}$ $\mathrm{H}_{2} \mathrm{SO}_{4} . T=25{ }^{\circ} \mathrm{C}$

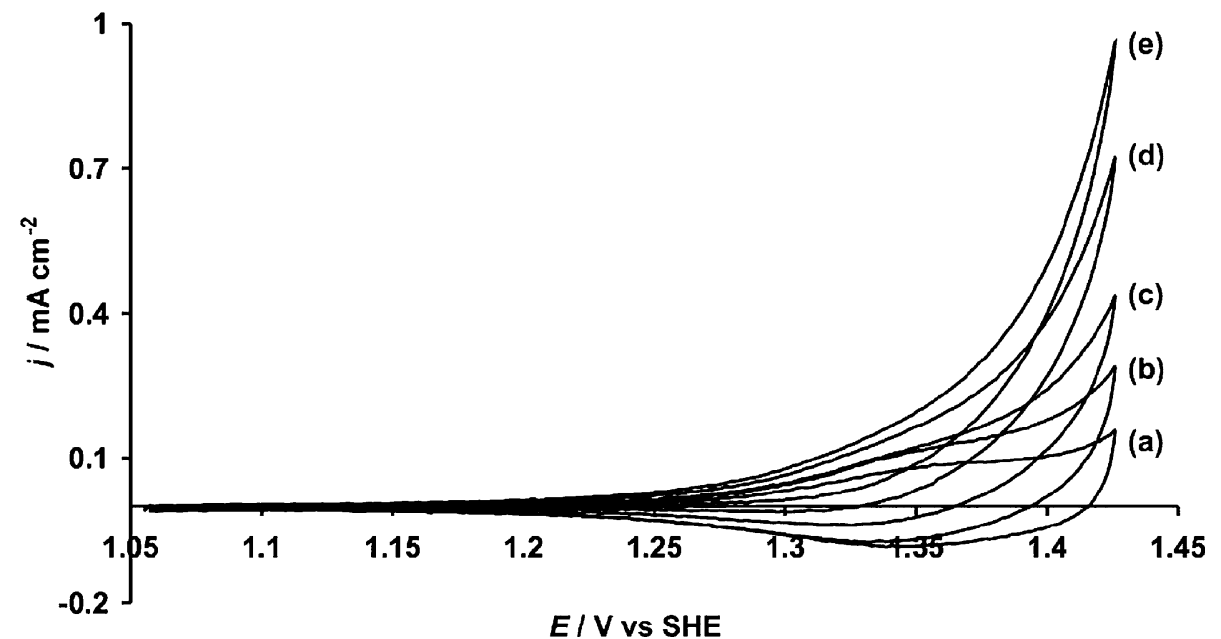

$\mathrm{IrO}_{3}+\mathrm{HCOOH} \rightarrow \mathrm{IrO}_{2}+\mathrm{CO}_{2}+\mathrm{H}_{2} \mathrm{O}$

This mechanism has been proved recently on TDIROF electrodes using ${ }^{18} \mathrm{O}$ labelling combined with DEMS measurements $[14,20]$.

Figure 8 shows $\mathrm{CV}$ obtained on AIROF in $1 \mathrm{M} \mathrm{H}_{2} \mathrm{SO}_{4}$ containing different concentration of formic acid. This figure clearly shows that the reduction peak related with the redox couple $\operatorname{Ir}(\mathrm{V}) / \operatorname{Ir}(\mathrm{IV})$ decreases strongly with increasing FA concentration. This is an indication that this redox couple is involved during FA oxidation on AIROF.

It is worthwhile to notice that the anodic oxide film was completely corroded at the end of these experiments.

\section{Conclusions}

The main conclusions can be summarized below:

- The surface redox activities involved on the AIROF are much faster than those involved on the TDIROF. Formation of a highly hydrated AIROF is certainly the main reason of the high surface activity of $\mathrm{IrO}_{2}$ film electrodes obtained by the anodic polarization of Ir metal (AIROF).

- The investigation of the oxygen evolution reaction in acid media has shown that both films show similar mechanisms (same Tafel slope of $40 \mathrm{mV} /$ decade) and specific electrocatalytic activity (similar normalized I-V curves).

- The involved surface redox couple during the anodic oxidation of formic acid (FA) depends strongly on the preparation mode of the $\mathrm{IrO}_{2}$ anodes. In fact, on TDIROF the oxidation of FA and the OER compete involving the same surface redox couple $\operatorname{Ir}(\mathrm{VI}) / \mathrm{Ir}(\mathrm{IV})$. However, this is not the case on the AIROF, where the oxidation of FA involves the $\operatorname{Ir}(\mathrm{V}) / \mathrm{Ir}(\mathrm{IV})$ surface redox couple and is not competing with the OER.

- Electrode stability measurements have shown that contrary to TDIROF, which are very stable under anodic polarization, the AIROF are rapidly corroded under anodic treatment. This corrosion is further enhanced in the presence of formic acid.

Acknowledgments The authors gratefully thank the Fonds National Suisse de la Recherche Scientifique for financial support as well as the Sensors, Actuators and Microsystems Laboratory, Institute of Microtechnology, University of Neuchâtel (SAMLAB-UNINE) for providing the iridium electrodes.

\section{References}

1. Trasatti S, O'Grady WE (1981) In: Gerisher H, Tobias CW (eds) Advances in electrochemistry and electrochemical engineering. Wiley, New York, p 177

2. Comninellis Ch, Nerini A (1995) J Appl Electrochem 25:23

3. Beck F, Schultz H (1984) Electrochim Acta 29:1569

4. Trasatti S (2000) Electrochim Acta 45:2377

5. Beer H, Hinden JM (1985) EU Patent EP 0,046,449 B1

6. Hinden JM et al (1984) US Patent 4,444,642

7. Hüppauff M, Lengeler B (1993) J Electrochem Soc 140:598

8. Silva TM, Simões AMP, Ferreira MGS, Walls M, Da Cunha Belo M (1998) Electroanal Chem 441:5

9. Jaksic MM, Johansen B, Tunold R (1994) Int J Hydrogen Energy 19:321

10. Cukman D, Vukovic M (1990) J Electroanal Chem 279:283

11. Kötz R, Neff H, Stucki S (1984) J Electrochem Soc 131:72

12. Kötz R (1990) In: Gerischer H, Tobias CW (eds) Advances in electrochemical science and engineering. Verlag Chemie, Heidelberg, p 109

13. Fierro S, Nagel T, Baltruschat H, Comninellis Ch (2007) Electrochem Commun 9:1969

14. Fierro S, Nagel T, Baltruschat H, Comninellis Ch (2008) Electrochem Solid-State Lett 11(7):E20

15. Fierro S, Ouattara L, Herrera Calderon E, Comninellis Ch (2008) Electrochem Commun 10:955 
16. Trasatti S (1980) In: Trasatti S (ed) Studies in physical and theoretical chemistry: electrodes of conductive metallic oxides Part A. Elsevier Scientific Publishing Company, Amsterdam, p 155

17. De Faria LA, Boodts JFC, Trasatti S (1996) J Appl Electrochem 26:1195
18. Vukovic M (1990) J Appl Electrochem 20:969

19. Gottesfeld S, Srinivasan S (1978) J Electroanal Chem 86:89

20. Fierro $S$ et al (2008) Electrochim Acta. doi: 10.1016/j.electacta. 2008.06.060 